\section{A De Facto Farewell}

First, a little history...My initial encounter with what we now call the MRS Bulletin occurred around mid-1979. As I recall, it consisted of four, or perhaps six, pages of newsletter which appeared to have been composed by typewriter and which by far devoted the larger fraction of available space to almost life-size photos of people rather than text.

Well, this may be a slight exaggeration, but the point is made. At the time MRS was its Fall Meeting, with lots of enthusiasm, no headquarters, and no regular staff (but plenty of irregulars). The meetings were managed by MRS devotees at Penn State and the Army's materials lab in Watertown, MA; the newsletter was composed aperiodically by Harry Leamy and friends at Bell Labs in Murray Hill, NJ.

Harry was president of MRS in 1983 and had seen much growth in the Society. A proceedings series had been started, the first Spring Meeting was on the horizon and the MRS headquarters was inaugurated in Pittsburgh in October of 1983. Having decided in 1981 that the newsletter needed some concentrated attention to turn it into a truly useful magazine, Harry obtained the services of a real writer and friend, Tim Middleton, to act as Bulletin editor. The Bulletin began to grow until the first issue to really look magazine-like (i.e., have a shiny cover) and, as it turned out, the last issue edited by Tim Middleton, appeared in September/October 1984.

Editorship was then formally assumed by Gail Oare, MRS director of publications at MRS headquarters, but Harry remained the driving force and gatherer of technical and editorial material. To further expand the magazine's resources, Harry formed an editorial board of international dimensions, appointed himself chairman, and informed the incoming 1985 president (yours truly) of the fait accompli. Insofar as technical content and opinion were concerned, Harry was the Bulletin's de facto technical editor. In one year he made tremendous strides in its coverage and value to MRS. Then he had to relinquish his role in favor of devoting more time to nonvolunteer work. (Yes, MRS volunteers have also been known to hold down real jobs.)

So in January of 1986, the de facto technical editorship fell to, or more precisely on, me. I hope it explains why I always seemed to behave as half-scientist and half-photographer/acquisitions editor at technical meetings. It has been a reward- ing, educational and, at times, humorous avocation. MRS Bulletin published 6 issues in 1986, 8 in 1987, and 12 per year thereafter. Guest-edited thematic issues were introduced by, in the first instance, imposing on our most intrepid volunteer, Woody White. Coverage of news and Society activities also grew in parallel with the astounding growth of MRS.

Kudos go to many for their relentless and sometimes feverish devotion to growing the Bulletin and I must mention them now. Gail Oare, whose management of all phases of Bulletin production was and is flawless, can also be credited with injecting sanity into the grandest of schemes so that they actually worked, with astounding effectiveness in politely prodding tardy contributors, and with the unparalleled equanimity to handle the frequent crises arising from competing demands on our publications crew. The Bulletin is perhaps the first known vessel to steer so straight a course with only one Oare. (Groan!)

Fran Wieloch, our assistant editor, has assumed an ever more crucial role as growth has proceeded. Not only has she read every word that finds its way into the Bulletin, but she has written many herself and repaired fractured text, found missing citations, and squeezed each issue's copy into our page budget. Most contributors to the Bulletin have had the pleasure of working with Fran on their articles.

To accomplish page layout, cover art, and all the other graphic chores that make up a magazine, we rely on Cindy Love, who can turn an odd collection of graphs and photos into an attractive cover and who can rescue the most illegible handdrawn figures for our authors.

Between the manuscript and the printed page is a vital link in the keyboard-bound fingers of Janice Dininny. On its way to typesetting, all the text passes through the word processor on her PC, having either been input by hand, read from diskette, or received over a telecommunications link. Janice also runs the Bulletin's book review process, from receipt of volumes and collecting suggestions for reviewers to distributing the books and keeping track of where everything is.

Many years ago, as the story goes, the principal soft drink manufacturer in the world decided its product was so much a household word that it no longer needed to advertise. Advertising stopped and sales dropped. Advertising has proved to be a must, both to introduce a new product and to maintain its recognition. This is a two-edged challenge for a magazine and the Bulletin is no exception. We must bring our medium to the attention of the wider technological community beyond our loyal member-readers. This increases the contents' value and visibility and helps to induce the best authorities to contribute. We also defray the cost of publication by selling advertising space to companies that market products of relevance to our readers. At the MRS Publications Committee's 1990 fall meeting, the Bulletin's balance sheet showed more than breakeven performance for the first time, and we have Mary Kaufold's perseverance and powers of persuasion to thank for reaching this milestone.

Thanks are also due to Peggy Costello, who, if there were a word-processing event in the Olympics, would be our entry in the 10,000-word dash; to copy editors Susan Morelli, Tom Loftus, and David Varner for so deftly passing the proofreading baton; and to artists Jennifer Probert and Wendy Appman for doing the same with the layout baton in their respective heats of the production relay. The job does not end, however, with the sprint to the printer, for then Shirley Krasa and Lucy Blackford, who can be deterred by neither rain nor snow nor computer downtime from ensuring that members and subscribers receive each issue, complete the monthly marathon. It has indeed been a special privilege and just plain fun to work with such excellent associates (who, by the way, have shown me the utmost forbearance in the face of criminally mixed metaphors).

All past and present members of the Bulletin's Editorial Boards and of the MRS Publications Committee must also be thanked for countless suggestions and well-executed chores. And, naturally, most important to our success have been the authors and guest editors who have volunteered their time, talents, and energies to produce leading-edge manuscripts for the enlightenment of us all.

After that long list of thanks, an expeditious exit seems in order, but this de facto farewell presages an orderly (isentropic, we hope) transfer of technical reins. I look forward to continuing in the job Harry Leamy devised as chair of the MRS Bulletin Editorial Boards. We have been extraordinarily fortunate to have attracted Dr. Elizabeth (Betsy) Fleischer to the post of technical editor. Her impressive background is described elsewhere in this issue. With the demise of de facto from the technical editorship, the future of our publication looks bright indeed.

E.N. KAUFMANN 